\title{
Renewal of aerosol data for ALADIN-HIRLAM radiation parametrizations
}

\author{
Laura Rontu ${ }^{1}$, Joni-Pekka Pietikäinen ${ }^{1}$, and Daniel Martin Perez ${ }^{2}$ \\ ${ }^{1}$ Finnish Meteorological Institute, Helsinki, Finland \\ ${ }^{2}$ Agencia Estatal de Meteorología, Madrid, Spain \\ Correspondence: Laura Rontu (laura.rontu@fmi.fi)
}

Received: 10 February 2019 - Revised: 10 June 2019 - Accepted: 12 June 2019 - Published: 5 July 2019

\begin{abstract}
Radiative transfer calculations in numerical weather prediction (NWP) and climate models require reliable information about aerosol concentration in the atmosphere, combined with data on aerosol optical properties. Replacement of the default input data on vertically integrated climatological aerosol optical depth at $550 \mathrm{~nm}$ (AOD550, Tegen climatology) with newer data, based on those available from Copernicus atmosphere monitoring service (CAMS), led to minor differences in the simulated solar irradiance and screen-level temperature in the regional climate model HCLIM-ALARO simulations over Scandinavia and in a clear-sky case study using HARMONIE-AROME NWP model over the Iberian peninsula. In the case study, replacement of the climatological AOD550 with that based on three-dimensional near-real-time aerosol mass mixing ratio resulted in a maximum reduction of the order of $150 \mathrm{~W} \mathrm{~m}^{-2}$ in the simulated local solar irradiance at noon. Corresponding maximum reduction of the screen-level temperature by almost two degrees was found. The large differences were due to a dust intrusion from Sahara, which is obviously not represented in the average climatological distribution of dust aerosol. Further studies are needed in order to introdude updated aerosol optical properties of all available aerosol types at different wavelengths, make them available for the radiation schemes of ALADIN-HIRLAM and test the impact on the predicted radiation fluxes.
\end{abstract}

\section{Introduction}

Numerical weather prediction (NWP) and climate models forecast shortwave (SW) and longwave (LW) radiative fluxes in the atmosphere and at the surface level. Atmospheric radiative transfer depends on the mixing ratios and optical properties of gases, clouds and aerosol particles. The importance of accounting for the radiative effect of aerosols in the NWP models has been documented in a multitude of recent articles, see for example Bozzo et al. (2017); Toll et al. (2016); Gleeson et al. (2016) and references therein. The required complexity of aerosol treatment in NWP models was recently discussed by Mulcahy et al. (2014).

Climatological fields of vertically integrated aerosol optical depth (AOD), based on Tegen et al. (1997), prescribed vertical distribution of AOD, based on Tanré et al. (1984) and inherent optical properties (IOPs) derived by Hess et al. (1998) have been used for parametrizations of aerosol radiative transfer in NWP and climate models (e.g. Zubler et al.,
2011; Bozzo et al., 2017; Bengtsson et al., 2017). However, the aerosol concentration in air can differ significantly from the climatological mean values when large amount of dust comes from a desert, large-scale forest fires occur, or a volcanic eruption injects ash high into the atmosphere. The impact of increased aerosol load on the radiative transfer may then increase significantly. In such cases, use of real-time aerosol data would be beneficial. On the other hand, climate simulations can still benefit from improved aerosol climatologies (e.g. Zubler et al., 2011).

Updated aerosol climatologies have resulted from reanalysis projects like Monitoring Atmospheric Composition and Climate (MACC, Inness et al., 2013). Recently, new sources of global satellite-based near-real-time data and updated climatology on aerosol distribution have become available via the Copernicus Atmosphere Monitoring Service (CAMS, CAMS, 2019). These data are produced by an advanced atmospheric chemical transport model, capable of forecasting 
the three-dimensional concentration of aerosol species, constrained by the assimilation of satellite-derived aerosol data (Flemming et al., 2017). Their usage opens new possibilities and poses new requirements for radiation and cloud microphysics parametrizations in both NWP and climate models.

In this study, we focus on renewal of the climatological and near-real-time aerosol input data for the radiation parametrizations within the Aire Limitée Adaptation Dynamique Développement International High-Resolution Limited Area Model (ALADIN-HIRLAM) forecast system. We summarise the status of aerosol usage in the radiation parametrizations in both the NWP (HARMONIE-AROME) and regional climate (HCLIM) model configurations of the system and report results of the first sensitivity experiments. At the first step of the ongoing work reported here, we have imported AOD550 fields for 11 tropospheric aerosol species and combined them into existing 4 aerosol categories, retaining the present simplified way to handle aerosol optical properties.

The rest of this article is outlined as follows. Section 2 summarises the present usage of aerosol information in the ALADIN-HIRLAM system. Section 3 describes the suggested renewal of AOD550 climatology and use of nearreal-time aerosol concentration. Section 4 presents results of some climate and NWP model experiments. Conclusions and outlook in Sect. 5 finish the study.

\section{Aerosols in the ALADIN-HIRLAM forecasting system}

Our aerosol studies were performed in specific NWP and climate model configurations of the ALADIN-HIRLAM forecasting system. For reference, Table 1 gives a glossary of the NWP and climate model configurations within the system. Details of our numerical experiments will be described in Sect. 4.

ALADIN-HIRLAM numerical weather prediction system (Termonia et al., 2018) includes parametrizations of the direct radiation effect due to aerosol absorption and scattering in the shortwave (SW) and longwave (LW) parts of the spectrum. HARMONIE-AROME configuration of the system (Bengtsson et al., 2017) applies by default an early version (cy25 from the year 2002, documented in ECMWF, 2018) of the Integrated Forecasting System (IFS) radiation scheme from the European Centre for Medium-Range Weather Forecasts (ECMWF). The regional climate model configuration HCLIM-ALARO (Lindstedt et al., 2015) uses by default the ALADIN radiation scheme, ACRANEB2 (Mašek et al., 2016; Geleyn et al., 2017). In all configurations of the ALADIN-HIRLAM system, the same aerosol climatology is currently used as input to the radiation schemes. Only the direct radiative effect due to aerosols is accounted for.

By default, monthly climatological maps of the vertically integrated aerosol optical depth (AOD) at the wavelength of
$550 \mathrm{~nm}$ (AOD550) for land (organic carbon), sea (sea salt), urban (black carbon) and desert (dust) particles, based on Tegen et al. (1997) are applied. The gridded global source data are given with $2.5^{\circ}$ resolution. In addition, uniformly distributed background AOD550 values for the stratospheric volcanic ashes (0.007) and sulphate (0.045) as well as for the tropospheric particles (land or organic aerosol type, 0.03 ) are assumed (see ECMWF, 2018). The vertical distribution of AOD550 is obtained by using prescribed exponential functions for each species following Tanré et al. (1984).

The wavelength-dependent aerosol inherent optical properties (IOP) are assumed constant in time and space and prescribed, ignoring possible humidity dependencies. The IOPs include the spectral dependence of AOD, single scattering albedo (SSA) and asymmetry factor $(g)$. Three-dimensional AOD fields are created for each wavelength and aerosol type. They enter the radiation schemes during the model timeintegration together with SSA and $g$. By default, $6 \mathrm{SW}$ and $6 \mathrm{LW}$ wavelengths for 6 aerosol species are accounted for. ACRANEB2 is a single-band scheme with only one SW and one LW spectral interval. For this scheme, the aerosol optical properties are remapped to the SW and LW bands by applying weighted spectral averaging.

\section{Renewal of the aerosol input data}

\subsection{Climatological aerosol optical depth}

Vertically integrated monthly climatology of the tropospheric mass mixing ratio (MMR) and prescribed mass extinction coefficient (ME) (Flemming et al., 2017; Bozzo et al., 2017), based on Copernicus Atmosphere Monitoring Service (CAMS) reanalysis over the years 2003-2011, were obtained from ECMWF (Alessio Bozzo, personal communication). Vertically integrated (total column) MMRs of 11 aerosol species, shown in Table 2, are represented in a global latitude-longitude grid of $2.5^{\circ}$ resolution. It was combined with ME at $550 \mathrm{~nm}$ (ME550) to obtain AOD550 as $\mathrm{AOD} 550=\mathrm{ME} 550 \times \mathrm{MMR}$ for each of the 11 species. As a first approximation, the 11 AOD550 fields were combined into the 4 categories of Tegen's AOD550 (land, sea, urban, desert). In this combination, sea salt and dust size bins were summed up, organic carbon was classified as land aerosol and black carbon as urban. Sulphates were divided half-and-half to the land and urban classes. The humiditydependencies of the hygroscopic aerosols were roughly approximated by assuming a constant relative humidity of 0.8 for land aerosol and 0.95 for sea aerosol. The resulting data set is further denoted by CAMSAOD climatology, and was applied with the default vertical distribution functions and the assumed AOD550 background values. 
Table 1. Glossary of the ALADIN-HIRLAM system.

\begin{tabular}{llll}
\hline Acronym & Full name & Purpose & Note \\
\hline ALADIN-HIRLAM & & Limited area nonhydrostatic NWP system & Termonia et al. (2018) \\
\hline ALADIN & $\begin{array}{l}\text { Aire Limitée Adaptation } \\
\text { Dynamique Développement International }\end{array}$ & Limited area NWP model and consortium & Since 1990 \\
\hline HIRLAM & High Resolution Limited Area Model & Limited area NWP model and consortium & Since 1985 \\
\hline AROME & $\begin{array}{l}\text { Application of Research } \\
\text { to Operations at Mesoscale }\end{array}$ & NWP configuration of ALADIN & Seity et al. (2011) \\
\hline ALARO & ALadin-AROme & NWP configuration of ALADIN & Since 2012 \\
\hline HARMONIE & $\begin{array}{l}\text { HIRLAM ALADIN Research } \\
\text { for Mesoscale NWP in Europe }\end{array}$ & Configuration within ALADIN-HIRLAM & Bengtsson et al. (2017) \\
\hline HARMONIE-AROME & & AROME configuration within HARMONIE & Regional climate model configuration \\
\hline HCLIM & HARMONIE Climate & HCLIM with physical parametrizations & Lindstedt et al. (2015) \\
\hline HCLIM-ALARO & & from ALARO & \\
\hline
\end{tabular}

Table 2. CAMS aerosol species.

\begin{tabular}{llr}
\hline Name & Description & $\begin{array}{r}\text { Size range } \\
(\mu \mathrm{m})\end{array}$ \\
\hline 01 SS1 & Sea Salt size1 & $0.03-0.5$ \\
02 SS2 & Sea Salt size2 & $0.5-5$ \\
03 SS3 & Sea Salt size3 & $5-20$ \\
04 DD1 & Dust size1 & $0.03-0.55$ \\
05 DD2 & Dust size2 & $0.55-0.9$ \\
06 DD3 & Dust size3 & $0.9-20$ \\
07 OM1 & Hydrophobic organic matter & $(0.02-0.2)$ \\
08 OM2 & Hydrophilic organic matter & $(0.02-0.2)$ \\
09 BC1 & Hydrophobic black carbon & $(0.005-0.5)$ \\
10 BC2 & Hydrophilic black carbon & $(0.005-0.5)$ \\
11 SU1 & Tropospheric sulphate & $(0.005-20)$ \\
\hline
\end{tabular}

Size estimates in parentheses are not used in definition of the CAMS aerosol categories but given here for information only.

\subsection{Near-real-time aerosol mass mixing ratio}

In order to test the impact of the near-real-time (the n.r.t.) aerosol concentration on the radiative transfer, threedimensional MMR fields from the CAMS forecast were introduced to HARMONIE-AROME simulations via the initial conditions and horizontal boundaries. The same 11 species that were used for preparation of the CAMSAOD climatology (Table 2) were included. The CAMS global data has horizontal resolution of ca. $40 \mathrm{~km}$ and 60 levels in vertical, the data are available with $3 \mathrm{~h}$ intervals from two daily analysisforecast cycles. In HARMONIE-AROME, the advection of the aerosol MMRs was treated by the equations of the atmospheric dynamics but no aerosol sedimentation process was parametrized. Thus, aerosol sinks were not considered but the MMRs, which were imported from the CAMS forecast at the initial time of each HARMONIE-AROME forecast, were only transported during the model run. Davies relaxation was imposed to both meteorological and MMR fields in the boundary zone.

The n.r.t. AOD550 at every level and grid-point was calculated by applying the climatological ME550 values to the n.r.t. MMR fields. Thus, the prescribed vertical distribution functions were not needed, but the values for 11 aerosol species were combined into the 4 Tegen species. The background values of tropospheric and stratospheric aerosol were still added and the prescribed wavelength-dependent aerosol IOPs were applied in the same way as for CAMSAOD. In the following, this 3-D data set is referred to as CAMSNRT.

\subsection{Inherent optical properties}

Gleeson et al. (2016) showed in a single-column HARMONIE-AROME study that the SW radiative transfer could be simulated realistically only when both AOD550 and the IOP values were realistic. Available CAMS aerosol data comprise prescribed IOPs for $14 \mathrm{SW}$ and $16 \mathrm{LW}$ spectral intervals between 0.2 and $1000 \mu \mathrm{m}$. For the hygroscopic aerosols, IOPs' dependence on atmospheric relative humidity is prescribed. Renewal of the IOPs is ongoing for HARMONIE-AROME, but in the present climate and NWP experiments the default IOPs for 6 aerosol classes and $6 \mathrm{SW}$ and $6 \mathrm{LW}$ spectral intervals without humidity dependency were still used (Sect. 2). 
(a)

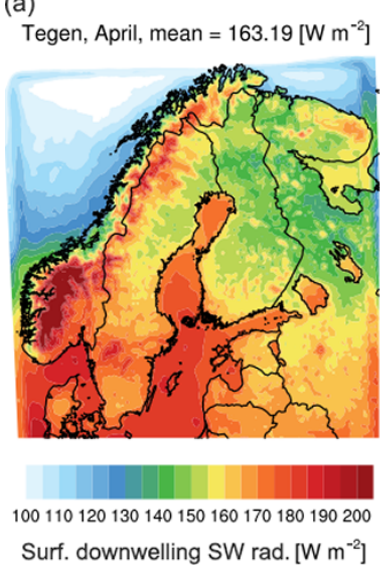

(b)

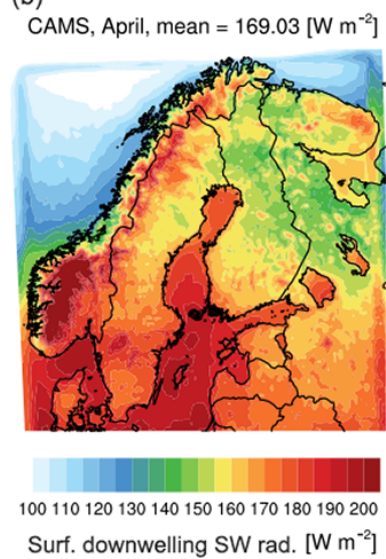

(c)

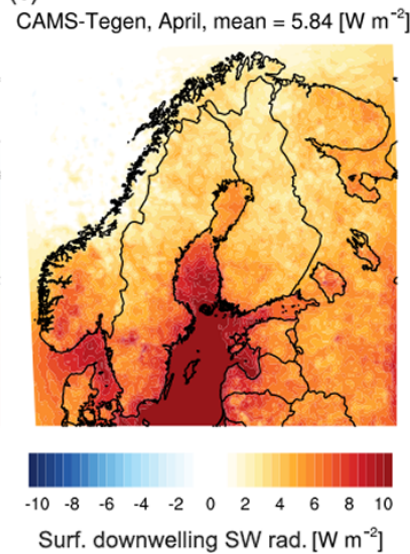

Figure 1. Monthly mean SWDS ( $\mathrm{W} \mathrm{m}^{-2}$ ) for 2012-2015, April: Tegen (a), CAMSAOD (b) and the difference CAMSAOD-Tegen (c).

\section{Numerical experiments}

\subsection{HCLIM-ALARO experiment with renewed AOD climatology}

A HARMONIE climate (HCLIM, Lindstedt et al., 2015) experiment was run over a Nordic domain for the period of July 2011-December 2015 (results were analysed for 2013-2015) to study the impact of the aerosol climatology update. Simulations, based on the version HCLIM38h1, rev. 15455, were run in hydrostatic mode with ALARO physical parametrizations, which include the ACRANEB2 radiation scheme. The horizontal resolution of ca. $12.5 \mathrm{~km}$ and 65 levels in vertical was used, and the lateral boundary forcing was obtained from ERA-Interim (Dee et al., 2011) reanalysis. The experiment was run in climate mode, i.e. in successive one-month-long cycles, that read the restart information from the previous month results. Two simulations with different monthly AOD550 climatologies - the default Tegen and the simplified CAMSAOD described above - were compared.

Figure 1 shows an example of monthly mean SW irradiance at the surface (SWDS) over the years 2013-2015 for the month of April, when the largest impacts were found. The maximum difference due to the use of different AOD550 data was ca. $10 \mathrm{~W} \mathrm{~m}^{-2}$ over the Baltic sea. This value was also the maximum over all monthly averages. Tegen and CAMSAOD data differ in the Nordic area mainly with respect to the categories of land and sea aerosol. The maximum values of land aerosol AOD550 are an order of magnitude larger according to the default Tegen climatology than according to CAMSAOD, while for the sea aerosol the opposite is true (not shown). Note that here the CAMSAOD land aerosol was assumed to represent all organic and half of the sulphate AOD550.

Screen-level temperature and precipitation by both simulations were compared to E-OBS V14 daily gridded obser- vation data (Cornes et al., 2018) for the years 2013-2015. In this comparison, both simulations show very similar results. For example in April, a mean bias of $T_{2} \mathrm{~m}$ was $-0.68 \mathrm{~K}$ for Tegen and $-0.61 \mathrm{~K}$ for CAMSAOD, with quite similar geographic distribution of the bias over the Nordic domain.

\subsection{HARMONIE-AROME using n.r.t. CAMS MMR}

Starting from the 19th of February 2017 a dust intrusion from the Sahara affected the south of the Iberian peninsula during 7 days. A HARMONIE-AROME (cy40h1.1) experiment using CAMSNRT data was set up over the Iberian domain (shown in Figs. 2 and 3) for 19-22 February 2017. Eight forecasts per day, each with forecast length of up to $24 \mathrm{~h}$, were run with horizontal resolution of $2.5 \mathrm{~km}$ and $65 \mathrm{lev}-$ els in vertical. Horizontal boundary data were obtained from IFS forecasts (of $9 \mathrm{~km}$ horizontal and 137-level vertical resolution) for the meteorological fields and from CAMS forecast (of $40 \mathrm{~km}$ horizontal and 60-level vertical resolution) for the aerosol fields with an interval of $3 \mathrm{~h}$. Aerosol MMR fields from CAMS forecast were introduced in the initial conditions and advected by the dynamics of the model (Sect. 3.2). A technical difficulty is that the spatial and temporal resolution of the IFS model is higher than that of the CAMS forecasts. The problem was solved by interpolating all boundary fields to the HARMONIE-AROME grid and blending the meteorological and aerosol input. Interpolations were done linearly, using the standard way of handling the lateral boundary data in HARMONIE-AROME.

The vertically integrated dust AOD550 at 12:00 UTC on 21 February 2017, given by the CAMS $12 \mathrm{~h}$ forecast that was initiated at 00:00 UTC (Fig. 2a), is compared to the suggested simplified CAMS climatology in February (Figure 2b) and to the default Tegen (Figure 2c) climatology. The maximum real-time values in the southeastern corner of the domain (over Sahara) were an order of magnitude greater (1.0) than the default climatological values $(0.1)$. The dust covering the 


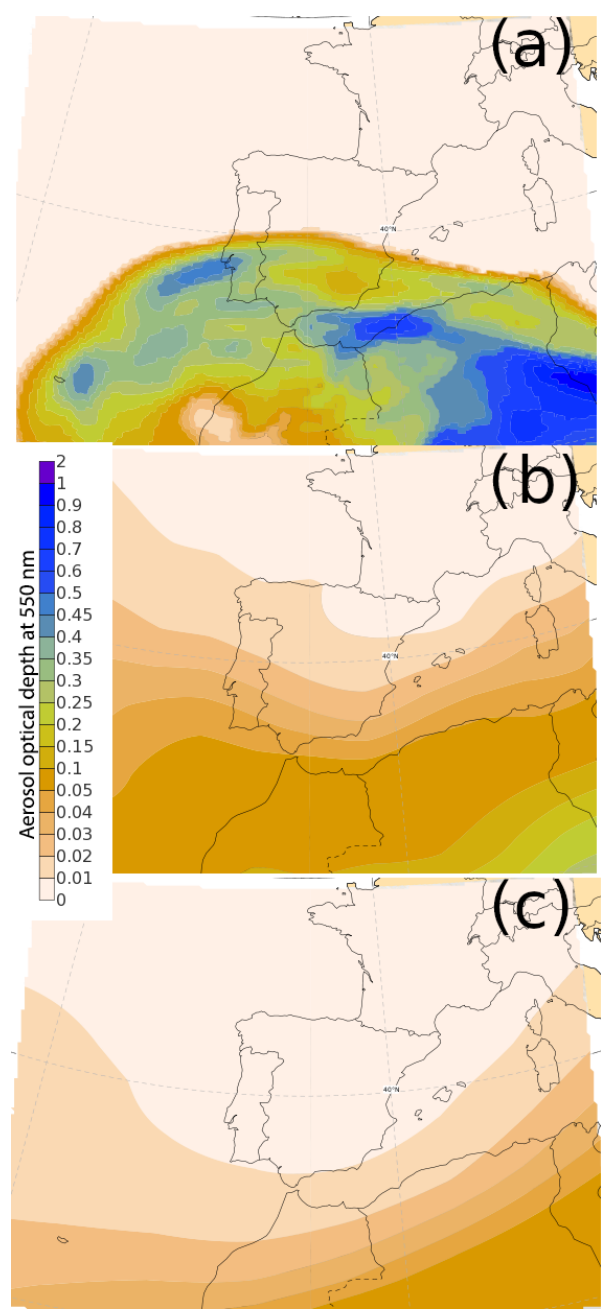

Figure 2. Dust AOD550 (dimensionless) at 12:00 UTC on 21 February 2017, based on CAMS $12 \mathrm{~h}$ forecast (a), CAMSAOD climatology in February (b) and the default Tegen climatology in February (c). The colour scale is given on the left column.

south of the Iberian peninsula is clearly seen. Here, the maximum AOD550 values from the n.r.t. data are about 0.4, from the simplified CAMS climatology about 0.04 and from the default Tegen climatology about 0.01 .

Figure 3 shows the difference of the $24 \mathrm{~h}$ average global irradiance at the surface, based on the $24 \mathrm{~h}$ CAMSNRT and Tegen forecasts which were started at 00:00 UTC on 21 February 2017. Negative values shown in blue in Fig. 3c over the dust-covered area indicate a reduction in the average global radiation. The maximum reduction of the clearsky flux from the default Tegen experiment (Fig. 3b) to the CAMS n.r.t. experiment (Fig. 3a) was $-154 \mathrm{~W} \mathrm{~m}^{-2}$, i.e. $60 \%$ of the maximum average global irradiance of the default. The domain-averaged irradiance decreased from $147 \mathrm{~W} \mathrm{~m}^{-2}$ of the Tegen experiment to $129 \mathrm{~W} \mathrm{~m}^{-2}$ of the n.r.t experiment. (The maximum increase of $166 \mathrm{~W} \mathrm{~m}^{-2}$ shown in red in Fig. 3c was due to the different position

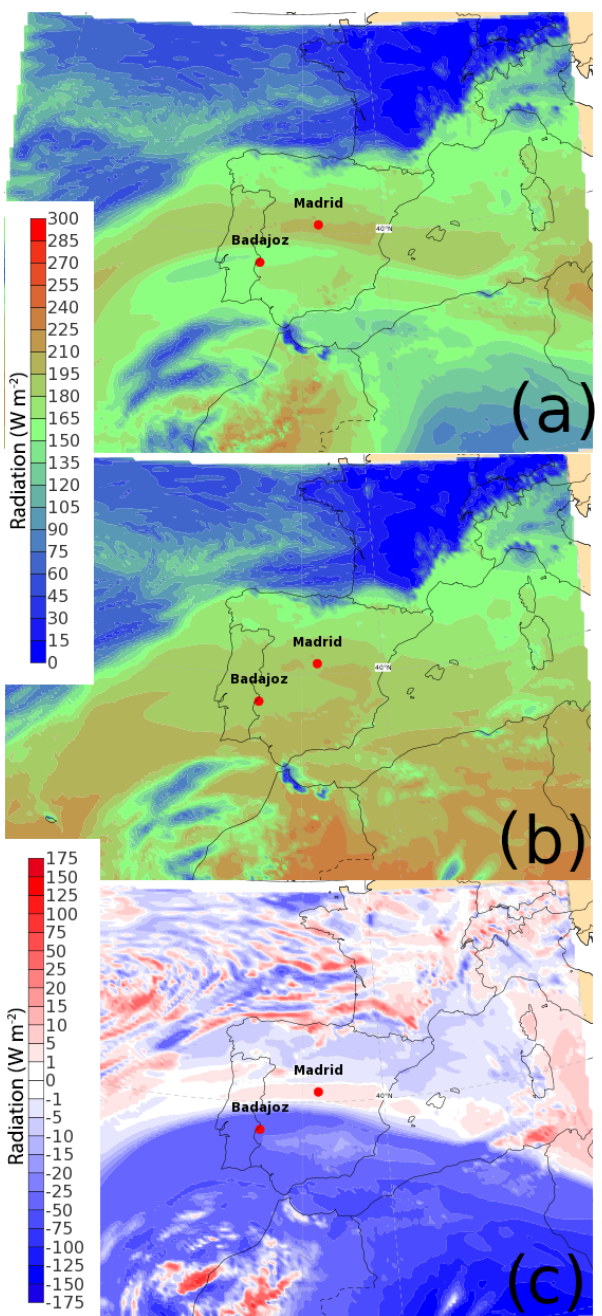

Figure 3. $24 \mathrm{~h}$ average global radiation $\left(\mathrm{W} \mathrm{m}^{-2}\right)$ from $24 \mathrm{~h}$ forecasts starting 00:00 UTC on 21 February 2017: CAMSNRT (a) and Tegen (b) experiments (upper colour scale) and their difference (c, lower colour scale). Locations of Badajoz and Madrid are marked with red dots.

of clouds close to the African west coast.) Reduction of the area-averaged global irradiance related to the use of simplified CAMS climatology instead of the default Tegen climatology was only $-3 \mathrm{~W} \mathrm{~m}^{-2}$ (not shown). The small impact is understandable because the difference in AOD550 between the n.r.t. and climatological values was much larger than the difference between the two climatologies.

Over the south of Spain and over Sahara there were almost no clouds during 20 and 21 February 2017, hence here the reduction of the surface shortwave radiation was due to the dust in the atmosphere. The simulated global radiation was compared with the radiation observations at several stations in the south of Spain. Figure 4 shows timeseries of the $1 \mathrm{~h}$ average global irradiance during four days measured at the station of Badajoz, compared to the forecast flux by CAMSNRT and Tegen experiments, extracted from the $24 \mathrm{~h}$ simulations 


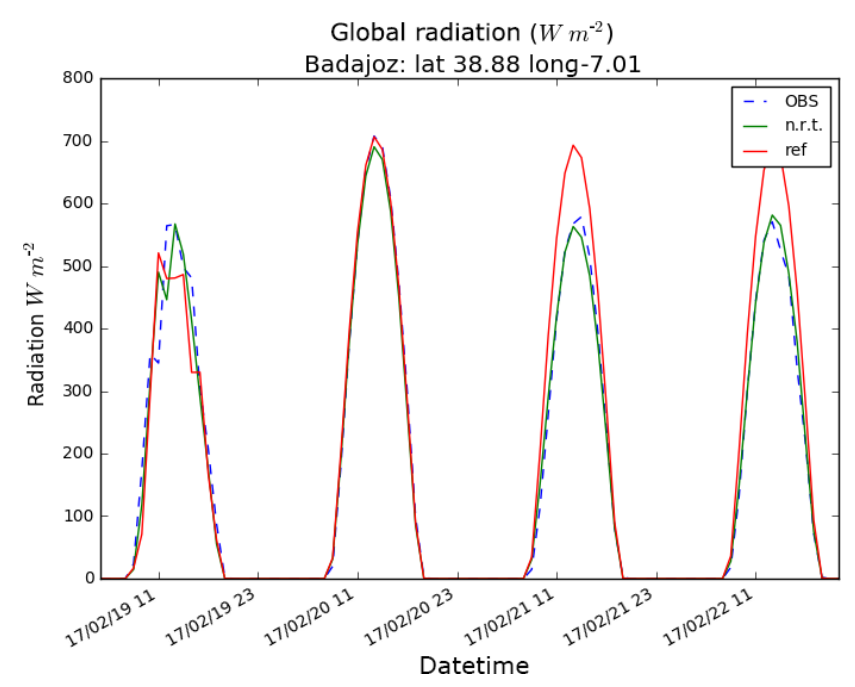

Figure 4. One-hour average global radiation $\left(\mathrm{W} \mathrm{m}^{-2}\right)$ for Badajoz station from 19 until 22 February: the default Tegen experiment (red), CAMSNRT experiment (green) and observations (dashed blue).

started at 00:00 UTC each day. The CAMSNRT experiment agreed with the observations better than the default Tegen experiment.

Screen-level temperature was also influenced. Figure 5 shows $T_{2} \mathrm{~m}$ time-series measured at an automatic station in Talavera la Real near Badajoz, compared to the forecasts by the two experiments. The reduction of the temperature around noon is clearly due to the dust intrusion. CAMSNRT experiment results agree very well with the observation especially in the middle of day. Similar agreement was found also at other stations (not shown).

\section{Conclusions and outlook}

Aerosol optical depth (AOD) data used for radiative transfer parametrizations was renewed in the ALADIN-HIRLAM forecast system. Sensitivity experiments with the climate model version (HCLIM-ALARO) and the NWP version (HARMONIE-AROME) showed differences in the downwelling shortwave radiation at the surface level and in the surface temperature. As expected, the differences due to update of the AOD550 climatology were small in the climate experiment run over a Nordic domain for 3 years. A significantly larger difference was found when the n.r.t. 3-D aerosol mass mixing ratio from Copernicus Atmospheric Monitoring Service was introduced and used to replace the climatological AOD in a case study during Saharan dust intrusion to Iberian peninsula. Results obtained by using the n.r.t. data led to radiation fluxes and screen-level temperatures that were closer to observations than those obtained by using the default aerosol climatology.

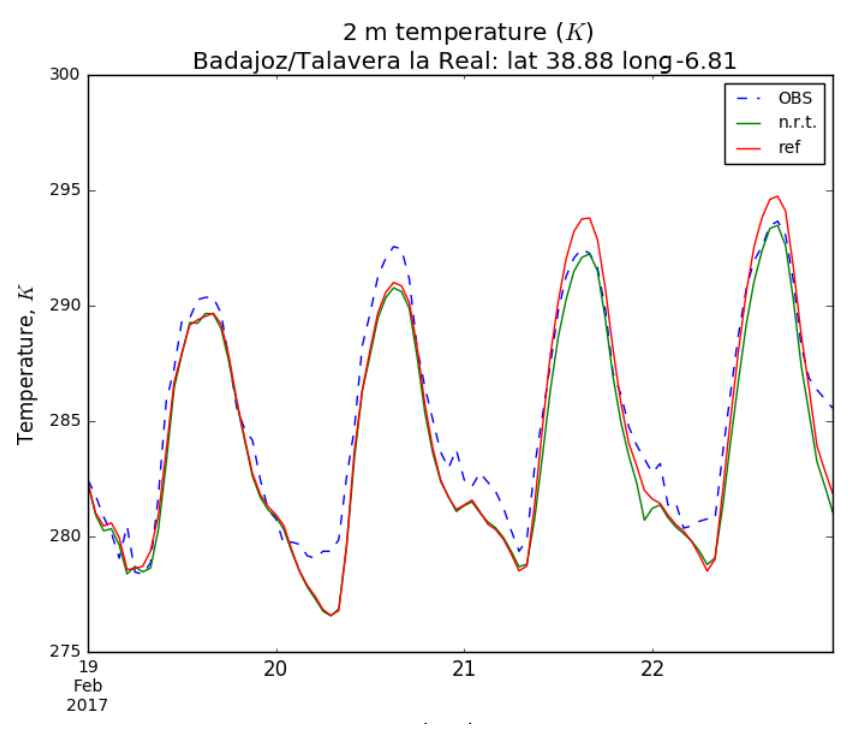

Figure 5. As for Fig. 4 but for the screen-level temperature at the automatic station Talavera la Real, Badajoz.

In order to fully benefit from the existing CAMS aerosol data it is necessary improve the treatment of the aerosol optical properties in the ALADIN-HIRLAM system. In the present experiments, simplifications concerning the aerosol inherent optical properties (IOP) were retained. The next step is to renew the prescribed values of the spectral dependence of AOD, single scattering albedo and asymmetry factor so that the wavelength and humidity dependencies will be taken into account in more detail for all available aerosol species. This will make the ad-hoc remapping of the eleven CAMS tropospheric aerosol classes to the four classes of the present Tegen climatology unnecessary and also allow the full use of the near-real-time aerosol mass mixing ratio data for radiative transfer calculations. Implementation of the updated optical properties to the available radiation schemes will then allow testing of the impact of varying aerosol concentrations and optical properties to the predicted radiation fluxes both in the weather forecast and climate applications of ALADINHIRLAM forecast system.

Historically, in NWP models the radiation and cloud microphysics have been treated separately, which may even have led to inconsistencies in treatment of cloud-radiation interactions. Usage of 3-D n.r.t. aerosol mass mixing ratio, obtained via the boundary and initial fields from the CAMS aerosol forecast, offers a possibility to unify the treatment of aerosols in the radiation and cloud microphysics parametrizations.

Data availability. Results of the numerical experiments and AEMET observations used for validation are available from the authors upon request. CAMS AOD data for the near-real-time experiment are available via their service https://www.copernicus.eu/en/ 
services/atmosphere (last access: 5 July 2019). CAMS aerosol climatology from ECMWF can be requested from the authors.

Author contributions. JPP prepared, run and described the climate experiment, DM prepared, run and described the Iberian case study and LR composed the text based on input from all authors.

Competing interests. The authors declare that they have no conflict of interest.

Special issue statement. This article is part of the special issue "18th EMS Annual Meeting: European Conference for Applied Meteorology and Climatology 2018". It is a result of the EMS Annual Meeting: European Conference for Applied Meteorology and Climatology 2018, Budapest, Hungary, 3-7 September 2018.

Acknowledgements. Our thanks are due to Alessio Bozzo (ECMWF) for advice and climatological CAMS data on aerosol concentration and optical properties. We thank Velle Toll for the pioneering work in introduction of CAMS AOD data to HIRLAM-ALADIN system. The support of the International HIRLAM-C and ALADIN programmes is acknowledged. We acknowledge the E-OBS dataset from the EU-FP6 project UERRA (http://www.uerra.eu, last access: 1 June 2019) and the Copernicus Climate Change Service, and the data providers in the ECA \& D project (https://www.ecad.eu, last access: 1 June 2019). We thank two anonymous reviewers whose suggestions helped to improve the contents and presentation of the manuscript.

Review statement. This paper was edited by Emily Gleeson and reviewed by two anonymous referees.

\section{References}

Bengtsson, L., Andrae, U., Aspelien, T., Batrak, Y., Calvo, J., de Rooy, W., Gleeson, E., Hansen-Sass, B., Homleid, M., Hortal, M., Ivarsson, K., Lenderink, G., Niemelä, S., Pagh Nielsen, K., Onvlee, J., Rontu, L., Samuelsson, P., Santos Muñoz, D., Subias, A., Tijm, S., Toll, V., Yang, X. and Ødegaard Køltzow, M.: The HARMONIE-AROME model configuration in the ALADINHIRLAM NWP system, Mon. Weather Rev., 145, 1919-1935, https://doi.org/10.1175/MWR-D-16-0417.1, 2017.

Bozzo, A., Remy, S., Benedetti, A., Flemming, J., Bechtold, P., Rodwell, M. J., and Morcrette, J.-J.: Implementation of a CAMS-based aerosol climatology in the IFS, Technical Memorandum 801, available at: https://www.ecmwf.int/en/elibrary/ 17219-implementation-cams-based-aerosol-climatology-ifs (last access: 1 June 2019), 2017.

CAMS - Copernicus Atmosphere Monitoring Service: Data, available at: https://www.copernicus.eu/en/services/atmosphere, last access: 1 June 2019.

Cornes, R. C., van der Schrier, G., van den Besselaar, E. J. M., and Jones, P. D.: An Ensemble Version of the E-OBS Temper- ature and Precipitation Data Sets, J. Geophys. Res.-Atmos., 123 9391-9409, https://doi.org/10.1029/2017JD028200, 2018.

Dee, D. P., Uppala, S. M., Simmons, A. J., Berrisford, P., Poli, P., Kobayashi, S., Andrae, U., Balmaseda, M. A., Balsamo, G., Bauer, P., Bechtold, P., Beljaars, A. C. M., van de Berg, L., Bidlot, J., Bormann, N., Delsol, C., Dragani, R., Fuentes, M., Geer, A. J., Haimberger, L., Healy, S. B., Hersbach, H., Hólm, E. V., Isaksen, L., Kållberg, P., Köhler, M., Matricardi, M., McNally, A. P., Monge-Sanz, B. M., Morcrette, J.-J., Park, B.-K., Peubey, C., de Rosnay, P., Tavolato,C., Thépaut, J.-N., and Vitart, F.: The ERA-Interim reanalysis: configuration and performance of the data assimilation system, Q. J. Roy. Meteorol. Soc., 137, 553597, https://doi.org/10.1002/qj.828, 2011.

ECMWF: IFS documentation, Part IV, Physical processes, available at: https://www.ecmwf.int/en/elibrary/ 18714-part-iv-physical-processes (last access: 10 April 2019), 2018.

Flemming, J., Benedetti, A., Inness, A., Engelen, R. J., Jones, L., Huijnen, V., Remy, S., Parrington, M., Suttie, M., Bozzo, A., Peuch, V.-H., Akritidis, D., and Katragkou, E.: The CAMS interim Reanalysis of Carbon Monoxide, Ozone and Aerosol for 2003-2015, Atmos. Chem. Phys., 17, 1945-1983, https://doi.org/10.5194/acp-17-1945-2017, 2017.

Geleyn J. F., Mašek, J., Brožková, R., Kuma, P., Degrauwe, D., Hello, G., and Pristov, N.: Single interval longwave radiation scheme based on the net exchanged rate decomposition with bracketing, Q. J. Roy. Meteorol. Soc., 143, 1313-1335, https://doi.org/10.1002/qj.3006, 2017.

Gleeson, E., Toll, V., Nielsen, K. P., Rontu, L., and Mašek, J.: Effects of aerosols on clear-sky solar radiation in the ALADINHIRLAM NWP system, Atmos. Chem. Phys., 16, 5933-5948, https://doi.org/10.5194/acp-16-5933-2016, 2016.

Hess, M., Koepke P., and Schult, I.: Optical Properties of Aerosols and Clouds: The Software Package OPAC, B. Am. Meteorol. Soc., 79, 831-844, https://doi.org/10.1175/15200477(1998)079<0831:OPOAAC>2.0.CO;2, 1998.

Inness, A., Baier, F., Benedetti, A., Bouarar, I., Chabrillat, S., Clark, H., Clerbaux, C., Coheur, P., Engelen, R. J., Errera, Q., Flemming, J., George, M., Granier, C., Hadji-Lazaro, J., Huijnen, V., Hurtmans, D., Jones, L., Kaiser, J. W., Kapsomenakis, J., Lefever, K., Leitão, J., Razinger, M., Richter, A., Schultz, M. G., Simmons, A. J., Suttie, M., Stein, O., Thépaut, J.-N., Thouret, V., Vrekoussis, M., Zerefos, C., and the MACC team: The MACC reanalysis: an $8 \mathrm{yr}$ data set of atmospheric composition, Atmos. Chem. Phys., 13, 4073-4109, https://doi.org/10.5194/acp13-4073-2013, 2013.

Lindstedt, D., Lind, P., Kjellström, E., and Jones, C.: A new regional climate model operating at the meso-gamma scale: performance over Europe, Tellus A, 67, 24138, https://doi.org/10.3402/tellusa.v67.24138, 2015.

Mašek, J., Geleyn, J. F., Brožková, R., Giot, O., Achom, H. O., and Kuma, P.: Single interval shortwave radiation scheme with parameterized optical saturation and spectral overlaps, Q. J. Roy. Meteorol. Soc., 142, 304-326, https://doi.org/10.1002/qj.2653, 2016.

Mulcahy, J. P., Walters, D. N., Bellouin, N., and Milton, S. F.: Impacts of increasing the aerosol complexity in the Met Office global numerical weather prediction model, Atmos. 
Chem. Phys., 14, 4749-4778, https://doi.org/10.5194/acp-144749-2014, 2014.

Seity, Y., Brousseu, P., Malardel, S., Hello, G., Benard, P., Bouttier, F., Lac, C., and Masson, V.: The AROME-France convectivescale operational model, Mon. Weather Rev., 139, 976-991, https://doi.org/10.1175/2010MWR3425.1, 2011.

Tanré, D., Geleyn, J. F. and Slingo, J.: First results of the introduction of an advanced aerosol-radiation interaction in the ECMWF low resolution global model, in: Aerosols and their climatic effects, edited by: Gerber, H. E. and Deepak, A., A. Deepak Publishing, Hampton, Va, USA, 133-177, 1984.

Tegen, I., Hoorig, P., Chin, M., Fung, I., Jacob, D. and Penner, J.: Contribution of different aerosol species to the global aerosol extinction optical thickness: Estimates from model results, J. Geophys. Res., 102, 23895-23915, https://doi.org/10.1029/97JD01864, 1997.
Termonia, P., Fischer, C., Bazile, E., Bouyssel, F., Brožková, R., Bénard, P., Bochenek, B., Degrauwe, D., Derkova, M., El Khatib, R., Hamdi, R., Mašek, J., Pottier, P., Pristov, N., Seity, Y., Smolíková, P., Spaniel, O., Tudor, M., Wang, Y., Wittmann, C., and Joly, A.: The ALADIN System and its canonical model configurations AROME CY41T1 and ALARO CY40T1, Geosci. Model Dev., 11, 257-281, https://doi.org/10.5194/gmd-11-2572018, 2017.

Toll, V., Gleeson, E., Nielsen K. P., Mannik, A., Mašek, J., Rontu, L., and Post, P.: Impacts of the direct radiative effect of aerosols in numerical weather prediction over Europe using the ALADIN-HIRLAM NWP system, Atmos. Res., 163-173, https://doi.org/10.1016/j.atmosres.2016.01.003, 2016.

Zubler, E. M., Lohmann, U., Lüthi, D., and Schär, C.: Intercomparison of aerosol climatologies for use in a regional climate model over Europe, Geophys. Res. Lett., 38, L15705, https://doi.org/10.1029/2011GL048081, 2011. 